\title{
Microbiologically, wine is a low food safety risk consumer product ${ }^{\mathrm{a}}$
}

\author{
Sara Azevedo, Tony Battaglene, and Greg Hodson \\ Secretary, FIVS, 18 rue d'Aguesseau, 75008 Paris, France
}

\begin{abstract}
Scientific studies indicate wine does not support the growth of pathogenic microorganisms such as Clostridium botulinum, Bacillus cereus, and Clostridium perfringens. Studies also show wine has antimicrobial properties due to its high acidity, polyphenol content, alcohol content, low redox potential, and preservative content. As a result, wine has been recognized as a consumer product with a low microbiological safety risk, and governments have issued guidance and employed proportionate regulatory frameworks from a food safety standpoint. Building complex food safety regulatory schemes which must be administered with scarce government resources is unnecessary for a product like wine, with a low microbial risk profile as identified by the general principles of risk management endorsed by the WHO and other international advisory bodies. Notwithstanding the inherent microbiological food safety of wine, at least from a bacterial standpoint, it remains essential that wine should be manufactured under appropriate good manufacturing practices.
\end{abstract}

\section{Properties of wine which make it a microbiologically low safety risk consumer product}

\subsection{High acid \& polyphenol content}

In 2011, the U.S. Food and Drug Administration (U.S. FDA) published a table on Limiting Conditions for Pathogen Growth [1] (Table 1) detailing the $\mathrm{pH}$ ranges required for the growth of several pathogens. Of the fifteen pathogens listed, most require a $\mathrm{pH}$ greater than 4.0 in order to grow. Wine is a highly acidic product, with a $\mathrm{pH}$ typically ranging from 3.1 to 3.9 [2-4], which means that due to its high acid content (low $\mathrm{pH}$ ) alone, most human pathogenic microorganisms cannot grow. As to their survival in wine, there is a large body of science that indicates Salmonella, Listeria monocytogenes, and Escherichia coli $\mathrm{O} 157: \mathrm{H} 7$ have the capacity to acclimate to acidic conditions, developing some level of resistance to acids [5]. However, research suggests that vegetative pathogens present at the $\mathrm{pH}$ levels of wine likely dieoff quickly within a few hours to a few days at room temperature. In addition, while the survival or growth of human sporeforming pathogens such as Clostridium botulinum and Bacillus cereus may be uncertain, it is clear that the spores of these organisms do not germinate and outgrow at the $\mathrm{pH}$ levels typical of wines. Considering the wide consumption of wines globally, the lack of any known outbreaks of illness from bacterial sporeforming pathogens in wine is empirical evidence that the risk of illness is very low to negligible.

${ }^{\mathrm{a}}$ Microbiologically, wine is a low food safety risk consumer product has been endorsed by the World Wine Trade Group, the International Wine Technical Summit Trade Barriers Working Group as well as the international wine and spirits trade association FIVS.
One study performed by the Department of Human and Environmental Sciences at the Ochanomizu University in Japan found, "food-borne bacteria were killed in both red and white wine within thirty minutes" [6]. Papadopoulou et al. explored the antimicrobial properties of phenolic compounds in wine and concluded, "The antimicrobial activity and the phenolic composition of the tested white and red wine extracts indicate that some phenolic acids have the potential to inhibit growth of certain pathogens such as Staphylococcus aureus, E. coli and Candida albicans strains" [7]. A study carried out in the Republic of Korea demonstrated that "Resveratrol among many polyphenol compounds of red wine exhibited notable antiviral effects against MNV-1 [murine norovirus-1] and FCV-F9 [feline calicivirus-F9]" [8] and another study published in the Journal of Food Science, examined the relative impacts of wine $\mathrm{pH}$, organic acid content, ethanol content and potential sulphur dioxide content in the inactivation of S. aureus and E. coli 0157:H7. Although $S$. aureus was significantly more resistant to wine treatment than E. coli $\mathrm{O} 157: \mathrm{H7}$, the study identified that wine $\mathrm{pH}$ was the most important characteristic in predicting inactivation for both organisms [9].

In short, these studies determined that important contributors to wine's antimicrobial properties include its high acidity (low $\mathrm{pH}$ ) and content of polyphenolic compounds. However, these properties are enhanced in wine because of additional anti-microbial properties, such as its alcohol (ethanol) content.

\subsection{Alcohol content}

The World Wine Trade Group (WWTG) [10] comprises eight member countries and has defined 'wine' as a product containing not less than $7 \%$ alcohol by volume. 


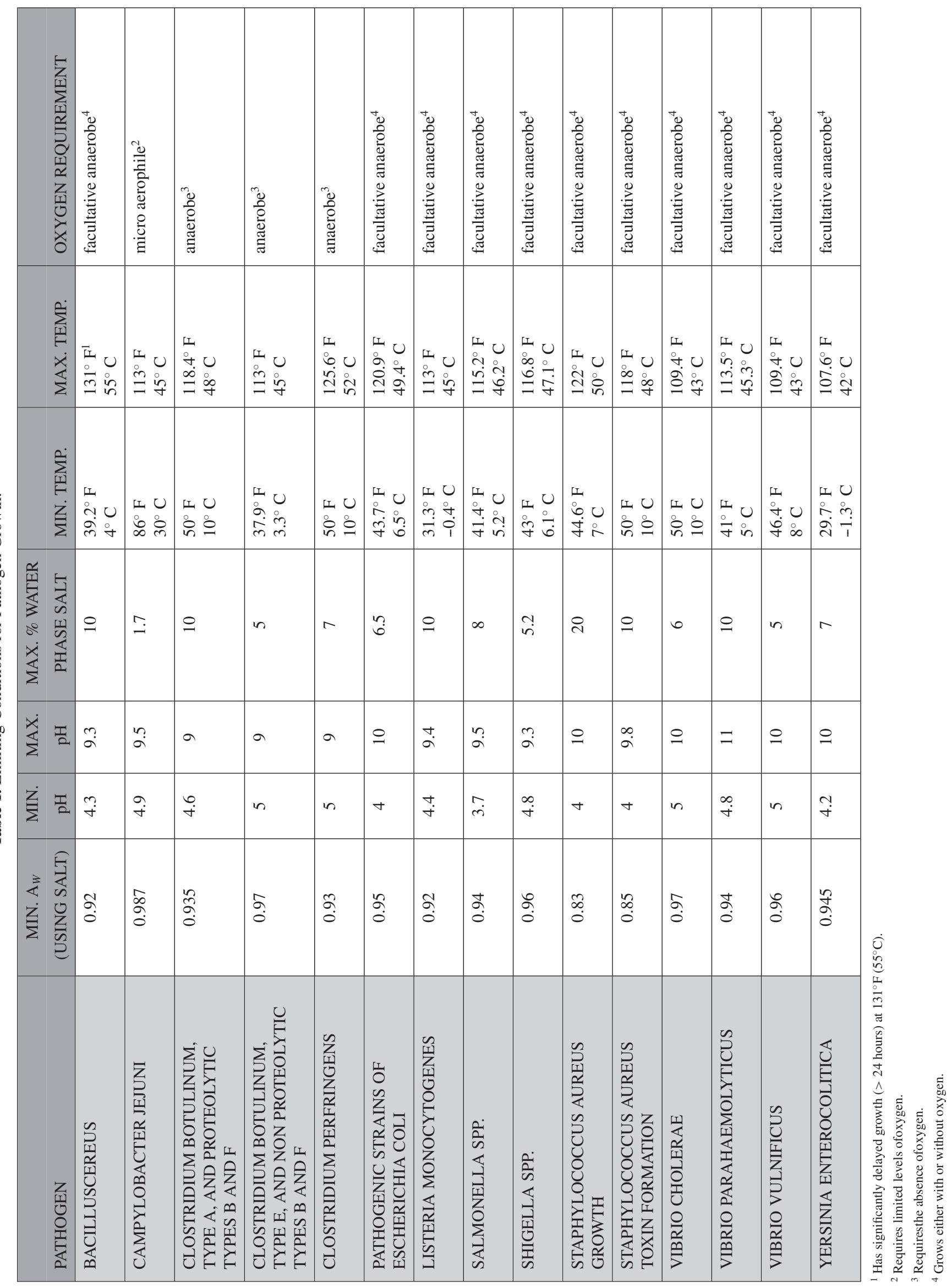


This is the product that is the subject of this paper. Products with lower alcohol outside the normal range of alcohol contents would need to be considered separately. The antimicrobial properties of highly concentrated alcoholic solutions have been recognized since the 1800's [11] but historically it has been used for this purpose at high concentrations. Nevertheless, several studies have suggested that alcohol at lower concentrations contributes to the antimicrobial characteristics of wine [12]. For example, a study published in Applied and Environmental Microbiology cited ethanol as an effective antimicrobial at levels as low as $2.5 \%$ [13].

A second study focused on several different strains of food borne pathogens and found Salmonella Typhimurium most sensitive to the alcohol in wine [14]. Scientists wrote, "When different combinations of ethanol, organic acids, and acidity were tested against the pathogens, it was found that a composition of $0.15 \%$ malic acid, $0.6 \%$ tartaric acid, $15 \%$ ethanol, and pH 3.0 has a strong bactericidal effect". They further stated that, "The compounds in the mixture seemed to act synergistically against the pathogens." These conditions model those found in wine.

Referencing studies like the ones discussed above, the Food and Agriculture Organisation (FAO) [15] acknowledged that most pathogenic microorganisms cannot grow in either alcoholic or acidic environments. When vegetative pathogens do survive under acidic conditions in wine, they often die off within a few hours to days at room temperature during storage and therefore likely do not pose a safety hazard. This is especially the case since, in general, wine is consumed several months after its production, which is a factor against pathogen survival.

\subsection{Additional anti-microbial properties of wine}

\subsubsection{Oxidation-Reduction potential}

In aqueous solutions, the oxidation-reduction potential (also called the redox potential) expresses the equilibrium that exists in a solution, at any given time, between oxidized and reduced substances. Wine generally has a low redox potential (about 200 to $300 \mathrm{mV}$ ) which might favour microbiological stability through the corresponding low levels of oxygen and the maintenance of desired levels of free sulphur dioxide [16]. (Redox potential as it applies to wine is not well understood, and according to Danilewicz [17], some even argue that the measurement of this property for wine is of very limited value. In these circumstances it is difficult to say with certainty the extent to which the low redox potential of wine contributes to its array of other anti-microbial properties, but it is included in this discussion for completeness.)

\subsubsection{Winemaking additions}

The use of additional anti-microbial substances in winemaking is permitted and commonly practiced in most winemaking countries around the world, adding to wine another layer of protection from the growth or survival of vegetative pathogens, and providing a further assurance of safety to wine consumers.

Sulphur dioxide (SO2) and sulphites (INS 220-228). Although naturally produced in small amounts by wine yeast during alcoholic fermentation, most of the sulphites found in wine are added by the winemaker, for two main purposes. Firstly, they are anti-microbial agents, used to help control the growth of undesirable yeasts and bacteria. Secondly, they act as antioxidants, safeguarding the wine's organoleptic properties and protecting it against browning [18].

Potassium sorbate (INS 202) is another substance sometimes used in winemaking to prevent spoilage by non-pathogenic yeasts and moulds. It is commonly used in sweeter wines. While it will not stop a fermentation which is already in progress, it will stop fermentation from restarting in wine containing residual sugar.

\subsection{Hurdle technology}

In microbiological terms, a hurdle is an obstacle which a microorganism must overcome in order to remain active in the food. Hurdle technology has been defined as an intelligent combination of microbiological hurdles which secures the microbial safety and stability as well as the organoleptic and nutritional quality and the economic viability of food products [19]. In simple terms, hurdle technology is a method of ensuring pathogens in food products can be eliminated, rendered harmless or controlled through the deliberate use of hurdles in a final product [20].

Former Director and Professor of the Federal Centre for Meat Research, Kulmbach, Germany, Lothar Leistner recognized multiple hurdles that may play a role in food preservation, including: heating, chilling, water activity, acidification, redox potential, preservatives, competitive flora, vitamins and nutrients [21]. As previously discussed, wine naturally includes several of these hurdles: high acidity, low redox potential, and preservatives (whether from fermentation (alcohol) or added (e.g. sulphites)).

In addition to the number of individual hurdles in a product, it is recognized that there can be significant synergistic effects when hurdles co-exist in a given food. Thus it can be expected that wine benefits from an even greater protective effect due to the synergy between its hurdles. In fact, this is exactly what was observed by scientist W. Dietze back in 1936:

"... red wine, which had the highest alcohol content but the lowest $\mathrm{H}$-ion concentration- that is, highest $\mathrm{pH}$ was the least active. Comparison of these results with those obtained in the preliminary experiments with alcohol showed that in general the disinfectant activity of wine was about three times as great as could be accounted for by their alcohol content. This indicates that the acid of the wine must have played a considerable part in the destruction of bacteria. In practice the final outcome is probably determined by the joint alcohol and acid concentrations" [22].

\section{Risk management for low safety risk consumer products}

Codex Alimentarius members have agreed upon several Principles and Guidelines for the conduct of microbiological risk assessment. These affirm that risk assessment is a key element in assuring that sound science is used to establish standards, guidelines and other recommendations for food safety to enhance consumer protection and facilitate international trade [23]. Additionally, the World 


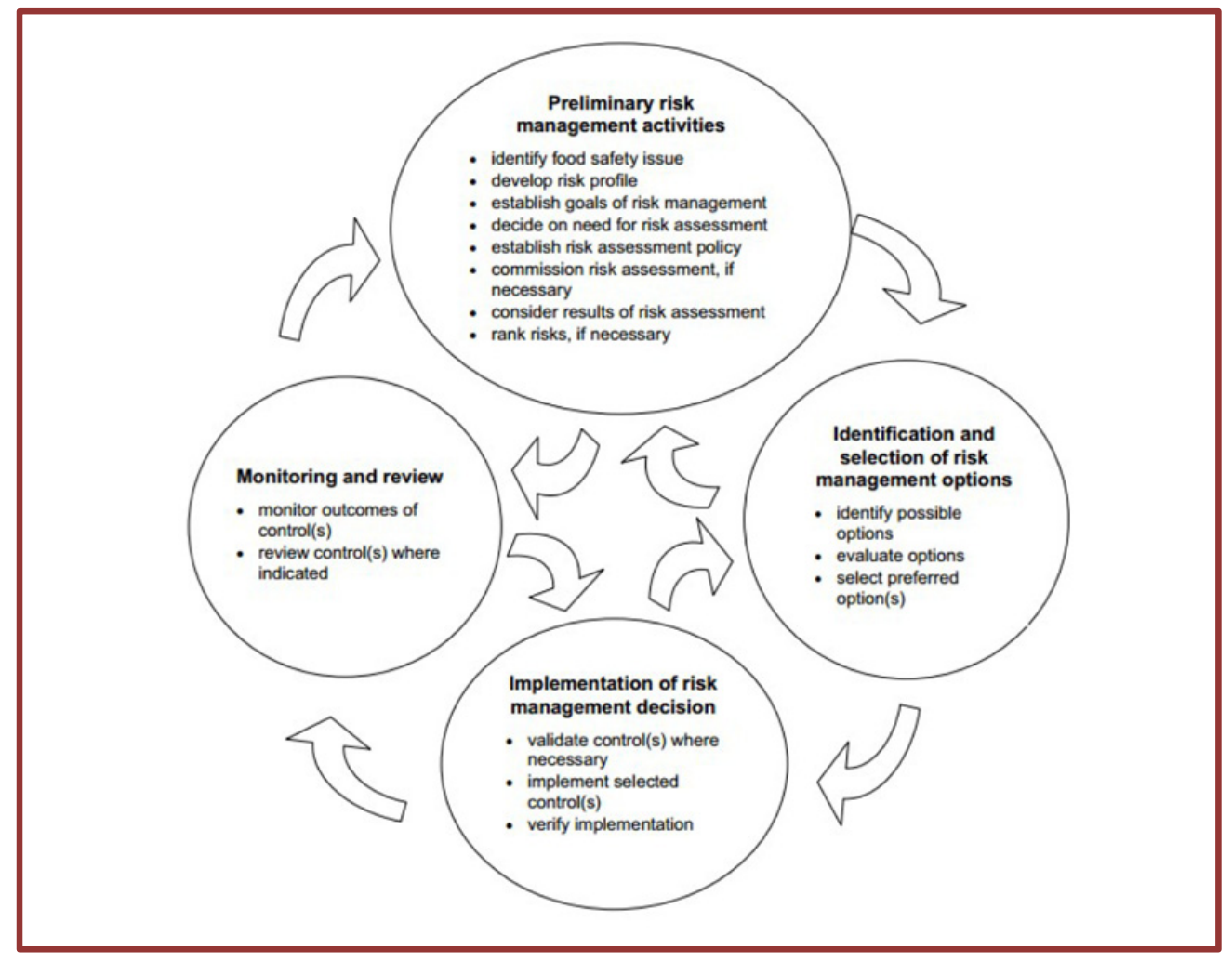

Figure 1. World Health Organization Risk Management Framework.

Health Organization (WHO) Food and Agriculture Organization of the United Nations (FAO) have carried out an expert consultation in which a generic framework for risk management was developed (Fig. 1) [24] in order to improve food safety regulators' understanding and use of risk management within their respective national food safety regulations.

According to this consultation, the primary goal of risk management associated with food is to protect public health by controlling such risks as effectively as possible through the selection and implementation of appropriate measures.

In the aforementioned expert consultation, 'risk ranking' is included in the preliminary risk management activities. The objective of risk ranking is the evaluation of the scientifically determined level of risk each issue presents to consumers, so that risk management resources can be optimally applied to reduce overall food related public health concerns [25]. This is commonly referred to as a 'risk-based' approach to public health protection. In other words, it means shifting government resources to more heavily regulate products which pose higher levels of food safety risk to consumer safety and streamlining approaches to other products which present a lower level of risk (i.e. wine).

\subsection{Regulatory frameworks}

Several countries have elaborated regulations and/or guidance on food safety which either specifically identify wine as having low microbial food safety risk, or else enable that conclusion to be deduced (based on the typical composition of wine) from the criteria established to enable risk characterization. This characterization of wine is, and should be, reflected in the control systems that are implemented for wine, and specifically in the nature and the extent of any testing that is required in connection with international trade in wine.

\subsubsection{Food Standards Australia New Zealand}

Standard 3.2.2 Food Safety Practices and General Requirements [26]. "Division 1- Interpretation and application" identifies potentially hazardous food as, "food that has to be kept at certain temperatures to minimise the growth of any pathogenic micro-organisms that may be present in the food or to prevent the formation of toxins in the food." Wine does not fit this definition as it does not require temperature-controlled storage for safety purposes, and would therefore not be considered a potentially hazardous food under this Standard.

\subsubsection{Wine Australia}

In the presentation entitled, "The Realm of the State Health Department," Slide 9 states: 'Wine is a LOW RISK food' [27].

\subsubsection{Government of South Australia: Food Policy and Programs Branch}

The South Australian Food Business Risk Classification [28]. has the following Definition on page 2: "Low risk foods are those that are unlikely to contain pathogenic organisms and will not support their growth, and will not introduce microbial, physical or chemical hazards to the foods they sell or handle." According to this definition, wine would be classified as a 'low risk food' from a microbial perspective. 


\subsubsection{Canadian Food Inspection System Implementation Group}

Food Retail and Food Services Code, Supplementary Note, Appendix A (page iv) [29].

"High risk foods are non-acidic or slightly acidic, moist, and protein foods. These food products require a number of complex control steps to ensure product safety (i.e., proper temperature requirements at various stages of preparation). These foods include meat and meat products, milk and milk products, eggs, poultry, fish and shellfish, as well as gravies, puddings, custards, cream-filled baked goods, potato and other mayonnaise-based salads, creambased soups and sauces.... Low risk foods are food products which do not pose significant health hazards by themselves."

Although wine is moist (liquid), it is a high acid food devoid of protein. It does not meet the criteria for a 'high risk food' according to the Canadian Food Inspection.

System Implementation Group definition and is more in line with the criteria outlined for a low risk food.

\subsubsection{The United States Food and Drug Administration}

The U.S. FDA publishes the Food Code, which represents the U.S. FDA's best advice for a uniform system of provisions that address the safety and protection of food offered at retail and in food service. The Food Code establishes criteria for the safe preparation, storage and display of foods that require time and/or Temperature Control for Safety (TCS Food) at retail. The Food Code definition of TCS Food specifies the intrinsic and extrinsic properties that can be used to determine if a particular food requires time and temperature control for safety. The Food Code recognizes that foods with a $\mathrm{pH}$ of less than 4.2 (that have not been heat treated or have been heat treated but not packaged) do not meet the definition of a TCS Food in terms of the control of both vegetative organisms and spores [30]. Such foods do not require further Product Assessment (PA) to establish that pathogen growth or toxin formation will not occur in the food and are not required to be stored and displayed at specified temperatures and times to prevent the growth of vegetative pathogenic microorganisms and their spores, where applicable. Since the $\mathrm{pH}$ of all wines falls in the range of 3.1 to 3.9, wine would be regarded as a non-TCS Food under the Food Code. Further, wine is usually packaged, is stable across typical storage temperature ranges over a long time periods and is commonly preserved with sulphur dioxide and sometimes with potassium sorbate, and scientific studies have confirmed that it does not support pathogen growth. While being considered a "non-TCS Food" does not automatically equate to a "low risk food", this approach confirms that wine will not support the growth of vegetative pathogenic microorganisms and spores of pathogenic microorganisms under normal storage and display conditions.

\subsubsection{Republic of the Philippines Food and Drug Administration}

In a 2014 the Republic of the Philippines Food and Drug Administration went one step further in their circular regarding procedures for electronic registration, where they specifically acknowledged wine's low-risk food categorization with the creation of a simplified registration process [31].

\section{Summary}

Wine is a complex product containing several components with antimicrobial properties. Its high acid content $(\mathrm{pH}$ 3.1 to 3.9), high polyphenol content, alcohol content (7\% to $24 \%$ ), low redox potential and sulphite content work synergistically to prevent the survival and growth of foodborne human pathogens. Research studies such as those cited in this paper show, and many regulatory frameworks recognize, that microbiologically, the "low risk food" category is appropriate for wine.

\section{References}

[1] Fish and Fishery Products Hazards and Control Guidance, (2011). U.S. Food and Drug Administration, 4: 420

[2] Waterhouse, A. L. (2002), Wine Phenolics. Annals of the New York Academy of Sciences, 957: 21-36

[3] Harbertson, Jim (2010), Managing High Acidity in Grape Must and Wine. Washington Viticulture and Enology Research and Extension

[4] Claudio Delfini, Joseph V. Formica (2001). Wine Microbiology Science and Technology, 103.

[5] Koutsoumanis, K.P. and Sofos, J.N. (2004), Comparative acid stress response of Listeria monocytogenes, Escherichia coli O157:H7 and Salmonella Typhimurium after habituation at different $\mathrm{pH}$ conditions. Letters in Applied Microbiology, 38: 321-326

[6] Yoshiko Sugita-Konishi, Yukiko Hara-Kudo, Tamami Iwamoto \& Kazuo Kondo (2001), Wine Has Activity against Entero-pathogenic Bacteria in Vitro but not in Vivo. Bioscience, Biotechnology, and Biochemistry, 65: 954-957

[7] C. Papadopoulou, K. Soulti and I. G. Roussis (2005), Potential Antimicrobial Activity of Red and White Wine Phenolic Extracts against Strains of Staphylococcus aureus, Escherichia coli and Candida albicans. Food Technol. Biotechnol, 43 (1) $41-46$

[8] Mi Oha, Ji-Hye Leeb, Seon Young Baea, Jong Hyeon Seok, Sella Kim, Yeon Bin Chung, Kang Rok Han, Kyung Hyun Kim, Mi Sook Chung (2015), Protective effects of red wine and resveratrol for foodborne virus surrogates. Food Control, 47: 502-509

[9] Waite JG, Daeschel MA (2007), Contribution of wine components to inactivation of food-borne pathogens. Journal of Food Science, 72(7):M286- 291

[10] World Wine Trade Group (2006), Initialling of English version of the Agreement on Requirements for Wine Labelling

[11] Yosef Ali, Michael J. Dolan, Eleanor J. Fendler, and Elaine L. Larson (2001), Alcohols. Disinfection, Sterilization, and Preservation, 229-249

[12] Ed. Mansel Griffiths (2005). Understanding Pathogen Behaviour Virulence, Stress Response and Resistance, 489-490 
[13] Indranil Chatterjee, Greg A. Somerville, Christine Heilmann, Hans-Georg Sahl, Hans H. Maurer, and Mathias Herrmann (2006), Very Low Ethanol Concentrations Affect the Viability and Growth Recovery in Post-Stationary-Phase Staphylococcus aureus Populations. Applied and Environmental Microbiology, 72: 2627-2636

[14] T. Moretro and M.A. Daeschel (2006), Wine is Bactericidal to Foodborne Pathogens. Journal of Food Science, 69: M251-M257

[15] Mike Battcock, Dr. Sue Azam-Ali (1998), Fermented Fruits and Vegetables: A Global Perspective. Food and Agriculture Organization of the United Nations

[16] Claudio Delfini, Joseph V. Formica (2001). Wine Microbiology Science and Technology, 128-130

[17] John C. Danilewicz (2012), Review of Oxidative Processes in Wine and Value of Reduction Potentials in Enology. Am. J. Enol. Vitic. 63:1

[18] Pat Henderson (2009), Sulfur Dioxide. The science behind this anti-microbial, anti-oxidant wine additive. Practical Winery \& Vineyard Journal, 2

[19] Leistner, Lothar (2000), Basic aspects of food preservation by hurdle technology. International Journal of Food Microbiology, 55(2000): 181-186

[20] H. Alakomi, E. Skytta, I. Helander \& R. Ahvenainen (2002), The Hurdle Concept. Minimal Processing Technologies in the Food Industry ed. T. Ohlsson, N. Bengtsson. 175-195

[21] Leistner Lothar (1995), Principles and applications of hurdle technology. In Gould GW (Ed.) New Methods of Food Preservation, Springer, 1-21
[22] Dietze, W (1936), Anitmictrobial properties of wine. British Medical Journal, 1 (3920): 372-373

[23] Principles and Guidelines for the conduct of microbiological risk assessment. Codex, document CAC/GL 30-1999

[24] Food safety risk analysis a guide for national food safety authorities (2006). FAO Food and Nutrition Paper 87

[25] Scientific Opinion on the development of a risk ranking framework on biological hazards (2012). European Food Safety Authority

[26] Australia New Zealand Food Standards Code Chapter 3 (Australia Only), Standard 3.2.2 Food Safety Practices and General Requirements

[27] The Realm of the State Health Department (2013), Wine Australia

[28] The South Australian Food Business Risk Classification (2013), Government of South Australia Food Policy and Programs Branch Public Health Services

[29] Food Retail and Food Services Code (amended 2004), Canadian Food Inspection System Implementation Group

[30] Food Code 2013 Recommendations of the United States Public Health Service (2013). Food and Drug Administration, 339

[31] FDA Circular No. 2014-029 Procedure for the Use of Electronic Registration (E-Registration) System for Raw Materials or Ingredients and Low Risk Pre- Packaged Processed Food Products, Republic of the Philippines Food and Drug Administration 